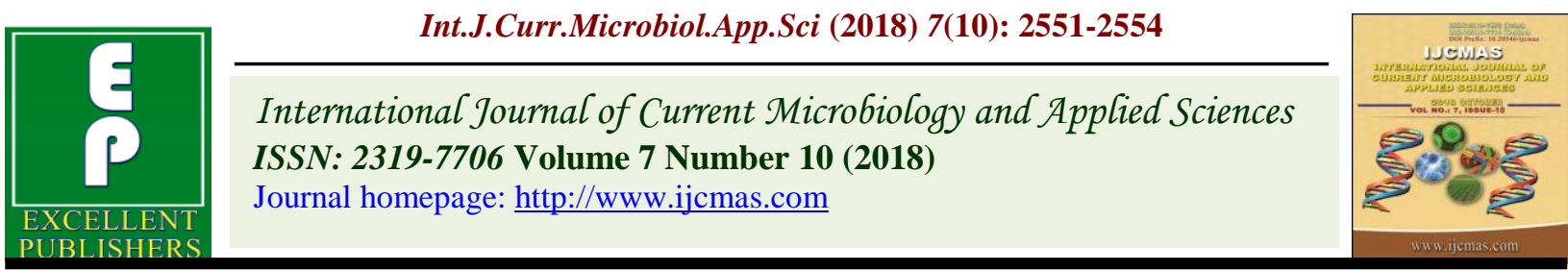

\title{
Impact of Eel Training Programmes on the Farming Community - A Follow up Study in Karnataka
}

\author{
C. Padma Veni* and K.S. Purnima
}

Faculty of Extension Education Institute, Rajendranagar, Hyderabad, Telangana, India

*Corresponding author

Key w or d s
Impact of EEl training
programmes, Farming
Community,
Karnataka

\section{A B S T R A C T}

Information, communication and population explosion along with science and technology in agriculture and allied sectors ale influencing the changes in the ideologies and objectives of the society. While the policies and programmes are formulated to generate and utilize the new resources, training of the people and personnel is seen as an integral part of development effort and also as means and ends of social change. Focusing on the faster growth of development in agriculture and allied sectors, a large number of training institutions have been established across the length and breadth of the country to achieve self-sufficiency in their respective sectors with the training effort at all levels. Still we need to meet the requirements of our larger population living below poverty line with continuous and well managed training programmes. Since training is a very costly affair involving number of inter connecting activities, it is highly essential for the training institutes and sponsoring organizations to know the effects of training programmes for the end users. With this in view, a two member team of EEl faculty (the authors) have taken up a follow-up study on training programmes conducted by Extension Education Institute, Rajendranagar. Hyderabad, Andhra Pradesh in three districts of Karnataka state namely Belgaurn, Bagalkote and Bijapur with an objective of assessing the extent of applicability of training programmes at field level and documenting the success cases. The overall applicability of the training programmes conducted by EEl was assessed from 58 trainees administering a structured questionnaire. Group wise discussions and presentations were also organized to bring out a few success cases that brought significant changes at field level. It was overwhelming to note that a majority of trainees (67\%) expressed EEl trainings were useful to a greater extent at field level because of need based, practically applicable and well-designed content of trainings. The follow up team also interacted with the farmers and observed changes that occurred due to various interventions and documented the success cases.

\section{Introduction}

Information, communication and population explosion along with science and technology in agriculture and allied sectors are influencing the changes in the ideologies and objectives of the society. While the policies and programmes are formulated to generate and utilize the new resources, training of the people and personnel is seen as an integral part of development effort and also as means and ends of social change. Focusing on, the 
faster growth of development in agriculture and allied sectors, a large number of training Institutions have been established across the length and breadth of the country to achieve self-sufficiency in their respective sectors with the training effort at all levels. Still we need to meet the requirements of our larger population living below poverty line with continuous and well managed training programmes.

Since training is a very costly affair involving number of inter connecting activities, it is highly essential for the training institutes and sponsoring organizations to know the effects of training programmes for the end users.

\section{Objectives of the study}

To assess the extent of applicability of training programmes at field level.

To document the success cases.

\section{Materials and Methods}

A two member team of EEl faculty visited four districts of Karnataka Viz., Bangalore, Belgavi, Bagalkot and Bijapur from $20^{\text {th }}$ to $23^{\text {rd }}$ July, 2010 and conducted follow up study of training programmes offered by EEl during the years 2007-08, 2008-09 and 2009-10. The Commissioners of agriculture and allied sectors were contacted well In advance for a schedule of visits for the interaction with the EEl trained officers and farmers at fields served by them. Questionnaire on the all training programmes organized during the said years and general proformae to know the overall applicability of EEl training programmes were prepared in consultation with institute faculty. Year wise and sector wise list of trainees undergone training at EEl were prepared. Visited the places in accordance with the schedule of visits and Interacted with trained officers and farmers in the field.

\section{Outcome of the follow up}

The outcome of the follow-up study is presented under the following heads:

Feedback from trainees in terms of learning's gained and its application

The feedback from the trainees on all the training programmes attended at EEl during the period under above mentioned four major areas was consolidated and presented below and based on the situation exercised the style of leadership and techniques of managing the conflicts at field level.

Used skill teaching on the topics Bio-pesticide preparations, spray solution preparations, seed treatment, grafting in horticulture crops and conducting germination tests etc.,.

Adopted extension talk, brainstorming, group discussions and role play whenever need raised.

Involved in preparing block and district action plans under ATMA.

Motivated the groups for the promotion of IPM and INM technologies.

Used mobile phones for disseminating IPM and INM technologies

\section{Conducted FFS on IPM and INM}

Adopted group approach to promote IPM and INM.

Promoted farmers to take organic certification

Disseminated market information on the crops to the farmers

Trained the farmers on Post-harvest technology development in horticulture crops 
viz. preparation of mixed fruit jam, squash, ketch-up, sauce, etc.,

Adopted team spirit, motivation, positive attitude, Interpersonal Skills, training etc. for the development of human resource

Encouraged value additions In cereals. fruits and vegetable etc...

Followed extension strategies like trainings, demonstrations.

Field visits and group formation

Published success stones, delivered radio talks and blended traditional and modern media for transfer of technology.

For example used mobile phone and dappu regarding prevailing market prices and wealth forecast In sericulture activity

Participated in community preparedness programme, shifted the people to the safe places during floods and

Carried relief operation programmes by following the steps taught in the disaster management training

Given equal opportunity to both men and women to voice their needs at field level and done gender analysis in agriculture and decided the areas where both need training and accordingly trained them after attending gender sensitization training.

\section{The quality and effectiveness of EEl training programmes}

The quality and overall effectiveness of EEl trainings were the two major parameters assessed from the focus group discussion, interactions and structured questionnaires administered to the trainees.

\section{Quality of the training programmes}

The group discussions conducted by EEl faculty with the trainees threw emphasis on the quality of EEl training. As revealed by the trainees, high quality could be attributed to EEl trainings for the following reasons.

Systematic procedure in terms of training needs assessment, formulation of objectives, training design, use of appropriate visual aids and interactive sessions.

Well proportion of theory and practical component.

High emphasis on informative and educative field and institutional visits for practical exposure

Interactive lectures supplemented with group and individual exercises, simulated exercises, management games, brainstorming sessions and FGOs

Knowledge and experience sharing by the trainees through individual and group presentations in every training programme

Assignments and back home planning as an integral part of every training for probe and widen thinking and vision of trainees towards sustainable development

Highly professional and dedicated institutional faculty for enhancing the knowledge, skills and attitude of the trainees.

\section{Effectiveness of EEI training programmes}

The effectiveness of EEl training was assessed in terms of their applicability in the field situation. Moreover, the success cases documented by the follow-up team provided an evidence for the effectiveness of $\mathrm{EEl}$ trainings. 
Table.1 The extent of applicability of EEl trainings at field level $(\mathrm{N}=58)$

\begin{tabular}{|c|c|c|c|}
\hline S. No & Extent of applicability & Frequency & Percentage \\
\hline $\mathbf{1}$ & To a greater extent & 39 & 67.25 \\
\hline $\mathbf{2}$ & To some extent & 19 & 32.75 \\
\hline $\mathbf{3}$ & Not at all applicable & - & - \\
\hline
\end{tabular}

\section{Extent of applicability of training}

It was overwhelming to note that a majority of trainees $(67 \%)$ expressed EEl trainings were useful to a greater extent at field level because of need based, practically applicable and welldesigned content of trainings. Few trainees (33\%) expressed to some extent EEl trainings were applicable at field level, owing to certain constraints faced by them. None of the trainees expressed Nil applicability of EEl trainings.

The trainees expressed the overall development of behavioral domains viz, knowledge, skills and attitude with EEl trainings is quite mentionable. With respect to new programmes such as Farmer field schools, Market led extension, Promotion of public private partnership, Promotion of entrepreneurship, Promotion of farmers groups and organizations, their knowledge increased considerably, the trainees further stated. Regarding skill development, tremendous improvement was achived by programmes such as Promotion of INM, IPM and IDM, Participatory watershed management, Promotion of organic farming, Farm journalism, Post-harvest technologies and value addition, up-gradation of communication skills, 1CM in commercial crops and Participatory training management. A significant attitudinal change was brought through programmes like Soft skills for personality development, Gender sensitization, Change management and Behavioral skills. This overall development in behavior with reference to knowledge, skills and attitude could be attributed to the effectiveness of EEl trainings.

The follow-up Visit undertaken in the state of Karnataka for the period 2007-2010 is an effective methodology not only for assessing the improvement in the performance of extension officers of agriculture and allied sectors, but also a means to promote healthy interaction and strengthen the linkages with the client state for the future ahead. Extension Education Institute, born to train middle level extension functionaries, also believes in a long term applicability, sustainability and development. During the Follow-up study, the extent of utility and application of knowledge and skills gained in the field situation were analyzed The follow-up visit of Karnataka state, threw light on the trust and regard, extension officers have on EEl, Rajendranagar and further strengthening this bond. The visits to farmer's field and interaction with farmers provided an evidence for the same. The Commissionerate of Agriculture, officer trainees from Agriculture and Allied sectors, farmers and all the concerned people who have cooperated for the successful completion of the follow-up, are hereby acknowledged.

\section{How to cite this article:}

Padma Veni, C. and Purnima, K.S. 2018. Impact of Eel Training Programmes on the Farming Community - A Follow up Study in Karnataka. Int.J.Curr.Microbiol.App.Sci. 7(10): 2551-2554. doi: https://doi.org/10.20546/ijcmas.2018.710.296 